\title{
Analysis of the influence of factors on agflation as a threat to food security: setting the task of system modeling in the context of globalization
}

\author{
Alexander Manilov ${ }^{1, *}$, Oleg Chekmarev², and Irina Shorenko ${ }^{1}$ \\ ${ }^{1}$ Saint-Petersburg State Agrarian University, Faculty of Electrical Power, Department of Higher \\ Mathematics, Saint-Petersburg, Russian Federation \\ ${ }^{2}$ Saint-Petersburg State Agrarian University, Faculty of Economics and management in the agro- \\ industrial complex, Department of Economics and Organization of Agricultural Production, Saint- \\ Petersburg, Russian Federation
}

\begin{abstract}
Research background: The problem of food security in the country is one of the most pressing problems of our time. At the moment, due to the pandemic, agflation has a very tangible increase in many countries of the world. The authors propose to apply a system analysis to study the mechanism of the influence of various factors on agflation and their interrelationships.

Purpose of the article: The aim of the article is to formulate the task of systemic modeling of agflation processes and its impact on the sustainability of food security.

Methods: The authors propose to draw up systems of econometric equations, which are modules combined into one system. Equations in these systems are constructed using regression analysis, and the dependent variables in one equation can be independent in another, and can also be used in different modules. Thus, there is a connection between various equations of one system and the modules of a single system. The whole system is built on the classical model of supply and demand, which reaches equilibrium when the values of the supply and demand variables are equal. But if these variables are equal, a rational level of food consumption by the population must be maintained for the sustainability of food security.

Findings \& Value added: The result is the formulation of the task of modeling the influence of factors on agflation. Due to the flexibility of the model, it is possible to trace the impact of each of the factors on the regulation of supply and demand, or how demand and supply are modified when several factors change.
\end{abstract}

Keywords: agflation; food security; system modeling; supply and demand

JEL Classification: $E 17 ; O 13 ; Q 11 ; Q 18$

${ }^{*}$ Corresponding author: manilov alex@mail.ru 


\section{Introduction}

The problem of food security in the country is one of the most pressing problems of our time. Ensuring a low level of agflation (inflation in the agricultural sector and the food sector) is an essential component for the sustainability of the state's food security. Now, in connection with the pandemic, agflation has a very tangible increase in many countries of the world, including Russia (Kenneth, 2015). To understand the mechanism of the influence of various factor signs on agflation and their interrelationships, one should, in our opinion, apply a systemic analysis. Previously, the reasons for the acceleration of agflation were named, such as higher energy prices, price increase for metals and capital goods in agriculture, higher incomes of the population, the use of agricultural products for purposes competing with food production (for example, the processing of agricultural raw materials into fuel), global warming and weather conditions, the processes of the international division of labor and globalization, the protection by states of their internal markets, the growth of the world's population and others (Baldos and Hertel, 2014).

The rise in energy prices has increased the cost of producing and transporting food. Because of the rise in oil prices, prices for natural gas rose, and as a result, prices for nitrogen and potash fertilizers rose (Aguinis et al., 2012).

Metal prices have increased, as a result of which the prices for agricultural machinery and equipment have increased.

Incomes of the population have increased, the structure of nutrition has changed in economically rapidly developing countries with a large population: India, China, and the countries of Southeast Asia. Previously, their main diet was rice and cereals (Baldos and Hertel, 2014). Now Asian "tigers" are switching to protein products: meat and milk, which require five times more agricultural area to produce than crop production alone. African populations witches from cassava to wheat (Aguinis et al. 2012).

The volume of agricultural products that are processed into biofuels has increased compared to previous periods. A number of leading agricultural countries (USA, Brazil and the European Union) began to allocate subsidies for the cultivation of genetically modified soybeans, sugar cane, rapeseed, and corn for these purposes. At the same time, the expansion of the total number of sown areas in agriculture is not observed, therefore, the sown areas that are used for food production are decreasing .

Global warming affects the climate. Together with soil erosion, this reduces the land suitable for crops on the borders with deserts and semi-deserts.

A number of countries have introduced special measures aimed at curbing production volumes in order to prevent overproduction and ruinous price drops for farmers.

The processes of the international division of labor and globalization led to the specialization of a number of countries in the extraction of raw materials or the production of a limited set of export goods for world markets. They also bought relatively cheap food produced, for example, in the United States(Nakamura et al., 2018). Therefore, domestic agriculture in many countries did not develop (Behrens et al., 2020).

With rising prices, agricultural producer states protect their domestic markets by imposing restrictions on food exports (for example, rice in Southeast Asia). This reduces the supply in the global food market, which further increases prices.

The planet's population is increasing in such a way that food production lags behind population growth (Allcott et al., 2019).

In addition, the positive growth of agflation is influenced by the political situation in the world (Zhiryaeva and Svetlov, 2020). Recently, various food sanctions have been introduced between some countries (Donovan K., 2021). 


\section{Methods}

As can be seen from the examples presented, the number of factors on which the level of prices for agricultural products and food can potentially depend is very large (Bustos et al., 2020). Therefore, forecasting changes and taking into account the mutual influence of these factors is a rather complex economic problem. To analyze such a complex task, the authors propose to build systems of interrelated (simultaneous) econometric equations, combined into various systems-modules. These systems contain equations in which dependent variables in one of the equations can be independent in the other and vice versa. In addition, variables, both dependent and independent can be used in various module systems. In other words, the system of joint, simultaneous equations (or the structural form of the model) usually contains endogenous and exogenous variables. Endogenous variables are dependent variables, the number of which is equal to the number of equations in the system. Exogenous variables are predefined variables that affect, but are not dependent on, endogenous variables. The classification of variables into endogenous and exogenous depends on the theoretical concept of the adopted model. Economic variables can appear in some equations as endogenous, and in others as exogenous variables. Non-economic variables (for example, climatic conditions, social status, gender, age category) are included in the system only as exogenous variables. The values of endogenous variables for the previous period of time (lagged variables) can be considered as exogenous variables. Thus, there is a connection between the equations of one system and different modules of the unifying system.

The coefficients of the structural model can be estimated in different ways depending on the type of system of simultaneous equations: indirect least squares method, two-step least squares method, three-step least squares method, maximum likelihood method with complete information, maximum likelihood method with limited information (Jaravel, 2019).

Due to the fact that most of the world's agricultural raw materials and foodstuffs are sold on the respective markets, it is advisable to form the entire system of models for assessing the factors of agflation and its forecasting for a given country on the classical model of supply and demand, which reaches an equilibrium position when the valuesof the demand variables and the offers are equal (Stephanie and Martín, 2021). It should be noted that if these variables are equal, a rational level of food consumption by the population should be maintained, which would provide the necessary level of food security and guarantee its sustainability (Behrens et al., 2020) Within the framework of this approach, any factor influencing supply or demand simultaneously affects the level of market prices, and, consequently, the economic availability of food (Gu, Zhang et al., 2021).

For clarity, the model will be written in the systems of equations linear, although this does not always correspond to reality. In other words, we will conditionally build linear models, even if the dependencies are not linear. To do this, you can use the linearization of the equations by taking the logarithm of both sides of the equalities (Masten, 2018). The signs of the coefficients in front of the explanatory variables are written as positive, but when calculating their quantitative estimates, they must be corrected.

The supply $(S)$ of food and agricultural products in the country in the context of globalization can be considered as a dependence on the volume of agricultural production $\left(s_{1}\right)$, imports $\left(s_{2}\right)$, production waste $\left(s_{3}\right)$ and stocks of finished products $\left(s_{4}\right)$ :

$$
S=a_{0}+a_{1} s_{1}+a_{2} s_{2}+a_{3} s_{3}+a_{4} s_{4}
$$

Demand $(D)$ taking into account international trade depends on the demand of the end consumer $\left(d_{1}\right)$, the volume of agricultural raw materials processed by the food industry $\left(d_{2}\right)$, own consumption within the producers of raw materials and food $\left(d_{3}\right)$, exports $\left(d_{4}\right)$ and processing and consumption waste $\left(d_{5}\right)$ :

$$
D=b_{0}+b_{1} d_{1}+b_{2} d_{2}+b_{3} d_{3}+b_{4} d_{4}
$$


Then the unifying system of equations has the form:

$$
\left\{\begin{array}{l}
S=a_{0}+a_{1} s_{1}+a_{2} s_{2}+a_{3} s_{3}+a_{4} s_{4} \\
D=b_{0}+b_{1} d_{1}+b_{2} d_{2}+b_{3} d_{3}+b_{4} d_{4} \\
S=D \\
S \geq T
\end{array}\right.
$$

where $T$ is the rational level of food consumption by the population.

Sentence $(S)$

The volume of agricultural production $\left(s_{1}\right)$ is determined by its own consumption $\left(s_{11}\right)$, costs $\left(s_{12}\right)$, the level of profitability $\left(s_{13}\right)$, stocks $\left(s_{14}\right)$ and expectations $\left(s_{15}\right)$ :

$$
s_{1}=a_{0}^{1}+a_{1}^{1} s_{11}+a_{2}^{1} s_{12}+a_{3}^{1} s_{13}+a_{3}^{1} s_{14}
$$

Own consumption $\left(s_{11}=d_{3}\right)$ is determined by the needs of production $\left(s_{111}\right)$ and the consumption of owners and employees $\left(s_{112}\right)$ :

$$
s_{11}=a_{0}^{11}+a_{1}^{11} s_{111}+a_{2}^{11} s_{112}, \text { or } s_{11}=a_{0}^{11}+a_{1}^{11} d_{3}+a_{2}^{11} s_{112}
$$

Production costs $\left(s_{12}\right)$ depend on material costs $\left(s_{121}\right)$, wages fund, taking into account the factors of international and internal labor migration $\left(s_{122}\right)$, equipment depreciation $\left(s_{123}\right)$, cost of financial resources, including the impact of cross-border capital flows $\left(s_{124}\right)$ and state regulation of production $\left(s_{125}\right)$ :

$$
s_{12}=a_{0}^{12}+a_{1}^{12} s_{121}-a_{2}^{12} s_{122}+a_{3}^{12} s_{123}+a_{3}^{12} s_{124}+a_{3}^{12} s_{125}
$$

(this case should be written in logarithmic form, the Cobb-Douglas production function will relate production volumes to the amount of resources used).

The level of profitability $\left(s_{13}\right)$ is formed under the influence of production costs $\left(s_{131}\right)$, prices and sales volumes $\left(s_{132}\right)$ :

$$
s_{13}=a_{0}^{13}+a_{1}^{13} s_{131}+a_{2}^{13} s_{132}
$$

(again, the logarithm is used, since the dependence is nonlinear).

Agricultural stocks $\left(s_{14}\right)$ are provided by carry-overs $\left(s_{141}\right)$, demand $\left(s_{142}=D\right)$, producers' expectations about the need to change the optimal stock balance of the next period $\left(s_{143}=s_{15}\right)$ and storage possibilities $\left(s_{144}\right)$ :

$$
\begin{gathered}
s_{14}=a_{0}^{14}+a_{1}^{14} s_{141}+a_{2}^{14} s_{142}+a_{3}^{14} s_{143}+a_{3}^{14} s_{144} \text { or } \\
s_{14}=a_{0}^{14}+a_{1}^{14} s_{141}+a_{2}^{14} D+a_{3}^{14} s_{15}+a_{3}^{14} s_{144}
\end{gathered}
$$

(again using logarithm).

Producers' expectations $\left(s_{15}\right)$ are determined by the inflation rate $\left(s_{151}\right)$, cyclical fluctuations economy in the country and in the world $\left(s_{152}\right)$, changes in demand $\left(s_{153}\right)$ (can be entered as) and changes in the supply of competitors, including foreign $\left(s_{154}\right)$ :

$$
s_{15}=a_{0}^{15}+a_{1}^{15} s_{151}+a_{2}^{15} s_{152}+a_{3}^{15} s_{153}+a_{3}^{15} s_{154}
$$

Then the second level module in sentence (S) has the form:

$$
\left\{\begin{array}{l}
s_{1}=a_{0}^{1}+a_{1}^{1} s_{11}+a_{2}^{1} s_{12}+a_{3}^{1} s_{13}+a_{3}^{1} s_{14} \\
s_{11}=a_{0}^{11}+a_{1}^{11} d_{3}+a_{2}^{11} s_{112} \\
s_{12}=a_{0}^{12}+a_{1}^{12} s_{121}+a_{2}^{12} s_{122}+a_{3}^{12} s_{123}+a_{3}^{12} s_{124}+a_{3}^{12} s_{125} \\
s_{13}=a_{0}^{13}+a_{1}^{13} s_{131}+a_{2}^{13} s_{132} \\
s_{14}=a_{0}^{14}+a_{1}^{14} s_{141}+a_{2}^{14} D+a_{3}^{14} s_{15}+a_{3}^{14} s_{144} \\
s_{15}=a_{0}^{15}+a_{1}^{15} s_{151}+a_{2}^{15} s_{152}+a_{3}^{15} s_{153}+a_{3}^{15} s_{154}
\end{array}\right.
$$




\section{Demand $(D)$}

End-user demand $\left(d_{1}\right)$ is characterized by prices for goods $\left(d_{11}\right)$, prices for goods substitutes and complementary goods $\left(d_{12}\right)$, consumer preferences $\left(d_{13}\right)$, disposable income $\left(d_{14}\right)$ and expectation $\left(d_{15}\right)$ :

$$
d_{1}=b_{0}^{1}+b_{1}^{1} d_{11}+b_{2}^{1} d_{12}+b_{3}^{1} d_{13}+b_{3}^{1} d_{14}+b_{5}^{1} d_{15}
$$

(again, the model is not linear, logarithm is used.)

The prices of goods $\left(d_{11}\right)$ are determined by demand $\left(d_{111}\right)$, supply $\left(d_{112}=S\right)$ and state production regulation of prices $\left(d_{113}\right)$

$$
d_{11}=b_{0}^{11}+b_{1}^{11} d_{111}+b_{2}^{11} d_{112}+b_{3}^{11} d_{113} \text {, or } d_{11}=b_{0}^{11}+b_{1}^{11} d_{111}+b_{2}^{11} d_{112}+b_{3}^{11} d_{113}
$$

The prices of substitutes and complementary goods $\left(d_{12}\right)$ are determined by the prices of imported products $\left(d_{121}\right)$, prices of exported products $\left(d_{122}\right)$, prices of substitute goods $\left(d_{123}\right)$ and prices of complementary goods $\left(d_{124}\right)$ :

$$
d_{12}=b_{0}^{12}+b_{1}^{12} d_{121}+b_{2}^{12} d_{122}+b_{3}^{12} d_{123}+b_{3}^{12} d_{124}
$$

Consumer preferences $\left(d_{13}\right)$ are formed under the influence of the value system $\left(d_{131}\right)$, public opinion $\left(d_{132}\right)$ and institutional framework $\left(d_{133}\right)$ :

$$
d_{13}=b_{0}^{13}+b_{1}^{13} d_{131}+b_{2}^{13} d_{132}+b_{3}^{13} d_{133}
$$

Disposable income $\left(d_{14}\right)$ depends on the wage fund and the level of wages $\left(d_{141}=s_{122}\right)$, property income $\left(d_{142}\right)$, grants and subsidies $\left(d_{143}\right)$, tax regime $\left(d_{144}\right)$ and entrepreneurial income (including the level of profitability) $\left(d_{145}\right)$ :

$$
\begin{gathered}
d_{14}=b_{0}^{14}+b_{1}^{14} d_{141}+b_{2}^{14} d_{142}+b_{3}^{14} d_{143}+b_{3}^{14} d_{144}+b_{5}^{15} d_{145}, \text { or } \\
d_{14}=b_{0}^{14}+b_{1}^{14} s_{122}+b_{2}^{14} d_{142}+b_{3}^{14} d_{143}+b_{3}^{14} d_{144}+b_{5}^{15} d_{145}
\end{gathered}
$$

Consumer expectations $\left(d_{15}\right)$ are determined by the inflation rate $\left(d_{151}\right)$, cyclical price fluctuations $\left(d_{152}\right)$ and surplus supply $\left(d_{153}\right)$ :

$$
d_{15}=b_{0}^{15}+b_{1}^{15} d_{151}+b_{2}^{15} d_{152}+b_{3}^{15} d_{153}
$$

Then the modulus of demand of the second level will have the form:

$$
\left\{\begin{array}{l}
d_{1}=b_{0}^{1}+b_{1}^{1} d_{11}+b_{2}^{1} d_{12}+b_{3}^{1} d_{13}+b_{3}^{1} d_{14}+b_{5}^{1} d_{15} \\
d_{11}=b_{0}^{11}+b_{1}^{11} d_{111}+b_{2}^{11} S+b_{3}^{11} d_{113} \\
d_{12}=b_{0}^{12}+b_{1}^{12} d_{121}+b_{2}^{12} d_{122}+b_{3}^{12} d_{123}+b_{3}^{12} d_{124} \\
d_{13}=b_{0}^{13}+b_{1}^{13} d_{131}+b_{2}^{13} d_{132}+b_{3}^{13} d_{133} \\
d_{14}=b_{0}^{14}+b_{1}^{14} s_{122}+b_{2}^{14} d_{142}+b_{3}^{14} d_{143}+b_{3}^{14} d_{144}+b_{5}^{15} d_{145} \\
d_{15}=b_{0}^{15}+b_{1}^{15} d_{151}+b_{2}^{15} d_{152}+b_{3}^{15} d_{153}
\end{array}\right.
$$

Similarly, system-modules for other factors affecting supply and demand, as well as systems-modules of a lower level, are compiled. As can be seen from the above, the relationship between equations arises not only within systems, but also between different modules. For a more descriptive view, consider Figure 1:

In the figure, the factors that are shaded are found in different modules. For example, own consumption $\left(s_{11}=d_{3}\right)$ affects the volume of agricultural production, as well as the final consumer demand, i.e. this factor appears in various systems-modules of demand $(D)$ and supply $(S)$.

The factor of expectations of producers about the need to change the optimal warehouse balance for the next period $\left(s_{15}=s_{143}\right)$ is involved in the formation of production volumes and producers' stocks. It takes place in equations of the system-module of the sentence $(S)$ of different levels.

Demand $\left(D=s_{142}\right)$ i is not only a productive indicator, the main one in its offshoot, but also affects the creation of producers' stocks. 
Production costs $\left(s_{12}\right)$, as well as consumer disposable income $\left(d_{14}\right)$, undoubtedly depend on the wage fund $\left(s_{122}=d_{141}\right)$. Thus, this factor is involved in different modules of demand $(D)$ and supply $(S)$.

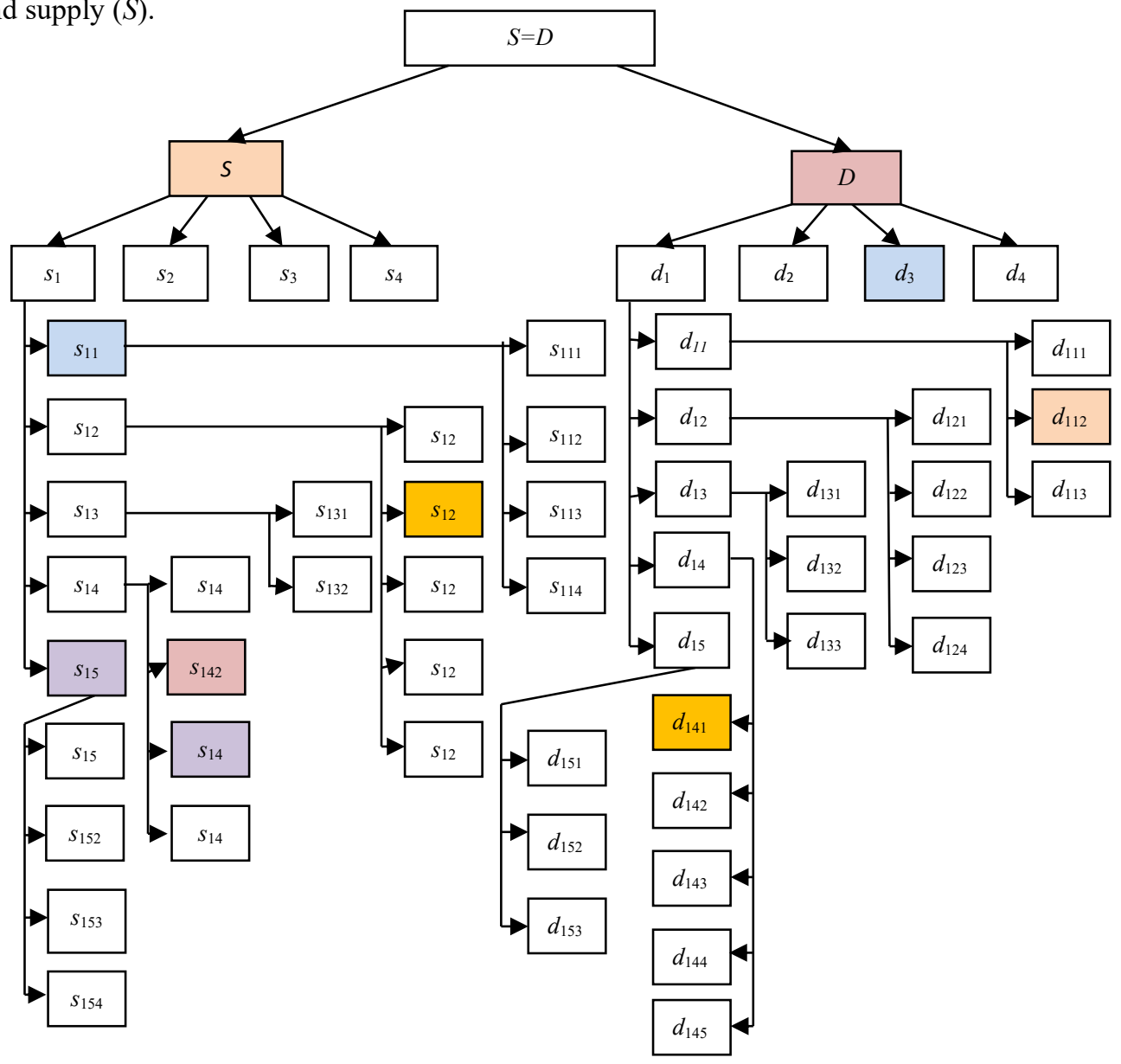

Figure 1. The relationship of features in the model.

Source: authors

So, different signs are found in different supply and demand modules. Such connections will be observed much more often at lower levels than was discussed in the article. In this regard, a change in the quantitative value of one factor will lead to a transformation of the quantitative values of other factors and effective indicators, not to mention a change in the values of several factors. Thus, it is possible to trace the influence of each of the factors on the result. In order to maintain a rational level of food consumption by the population, it is necessary to maintain or decrease the value of the equilibrium price in terms of the purchasing power of the population, which is achieved by balancing supply and demand in a known range. To regulate these indicators, you can use well-studied economic and mathematical planning methods. For example, methods of linear programming, simulation modeling, multiparameter problems of nonlinear optimization. In the context of economic globalization, successful planning for the sustainability of ensuring the economic accessibility of food through control over supply and demand, and, therefore, over the price level can be carried 
out not only by state authorities, but also by forms of horizontal integration of consumers and producers of products (unions, associations, cooperatives, etc.).

\section{Results and Discussions}

Summing up the results of the study, it can be argued that the proposed approach to system modeling has the following advantages:

1. Systematic consideration of the factors of agflation as a threat to the economic availability of food in the country in the context of global markets.

2. It is possible to modify the model depending on the specific conditions for ensuring food security of individual countries and, if necessary, to introduce new variables into it.

3. Optimization tasks can be solved both on individual modules and on the entire system as a whole, which undoubtedly facilitates their solution.

The presented approach to the formulation of the problem of system modeling in the context of globalization, despite the existing advantages, also has potential disadvantages, among which the following should be noted:

1. Large requirements for the amount of information used in the analysis;

2. Limited application of the model for countries with a significant expression of the factor of self-sufficiency of citizens with food, undeveloped market exchange.

3. The need for more detailed studies of the relationships between individual indicators of the proposed system.

Despite this, the development of the statistical services of countries and the processes of digitalization of the economy make it possible to count on a gradual smoothing of the first limitation. The fact that in a significant number of countries of the modern world a high level of marketability of agricultural and food production has already been formed allows avoiding the second limitation within this framework. As for the last limitation, it is a dialectical consequence of the processes of development and complication of scientific knowledge and can be considered as an incentive for further research in this area.

\section{References}

1. Aguinis H., \& Forcum L. E., Joo, H. (2012). Using Market Basket Analysis in Management Research. Journal of Management, 39(7), 1799-182.

2. Aguinis, H., Forcum, L. E., Joo, H. (2013). Using Market Basket Analysis in Management Research. Journal of Management, 39(7), 1799-1824.

3. Allcott, H., Diamond, R., Dubé, J. P., Handbury, J., Rahkovsky, I., \& Schnell, M. (2019). Food Deserts and the Causes of Nutritional Inequality. The Quarterly Journal of Economics, 134(4), 1793-1844.

4. Baldos, U. L. C., \& Hertel, T. W. (2014). Global food security in 2050: the role of agricultural productivity and climate change. Australian Journal of Agricultural and Resource, Economics, 58(4), 554-570.

5. Behrens, K., Mion, G., Murata, Y., \& Suedekum, J. (2020). Quantifying the Gap Between Equilibrium and Optimum under Monopolistic Competition. The Quarterly Journal of Economics, 135(4), 2299-2360.

6. Brauer, M., \& Wiersema, M. (2018). Analyzing Analyst Research: A Review of Past Coverage and Recommendations for Future Research. Journal of Management, 44(1), 218-248.

7. Bustos, P., Garber, G., \& Ponticelli, J. (2020). Capital Accumulation and Structural Transformation. The Quarterly Journal of Economics, 135(2), 1037-1094. 
8. Donovan, K. (2021). The Equilibrium Impact of Agricultural Risk on Intermediate Inputs and Aggregate Productivity. The Review of Economic Studies, 88(5), 275-2307.

9. Gu, H., Zhang, T. C., Lu, C., \& Song, X. (2021). Assessing Trust and Risk Perceptions in the Sharing Economy: An Empirical Study. Journal of Management Studies, 58(4), 1002-1032.

10. Jaravel, X. (2019). The Unequal Gains from Product Innovations: Evidence from the U.S. Retail Secto. The Quarterly Journal of Economic, 134(2), 715-783.

11. Kenneth, A. R. (2015). Food Security as Basic Goods Provision. World Medical \& Health Policy, 7(3), 169-170.

12. Masten, M. A. (2018). Random Coefficients on Endogenous Variables in Simultaneous Equations Models. The Review of Economic Studies, 85(2), 1193-1250.

13. Nakamura, E., Steinsson, J., Sun, P., \& Villar, D. (2018). The Elusive Costs of Inflation: Price Dispersion during the U.S. Great Inflation. The Quarterly Journal of Economics, 133(4), 1933-1980.

14. Schmitt-Grohé, S., \& Uribe, M. (2021). Multiple Equilibria in Open Economies with Collateral Constraints. The Review of Economic Studies, 88(2), 969-1001.

15. Zhiryaeva, E. V., \& Svetlov, N. M. (2020). The effect of sanctions on Russian agricultural imports. Vestnik Sankt-Peterburgskogo Universiteta. Ekonomika, 36(4), 653-674. 